Supplement of

\title{
Analysis of soil hydraulic and thermal properties for land surface modeling over the Tibetan Plateau
}

\section{Hong Zhao et al.}

Correspondence to: Hong Zhao (h.zhao@utwente.nl)

The copyright of individual parts of the supplement might differ from the CC BY 4.0 License. 
Supplement

Table S1 Information of the exiting soil datasets

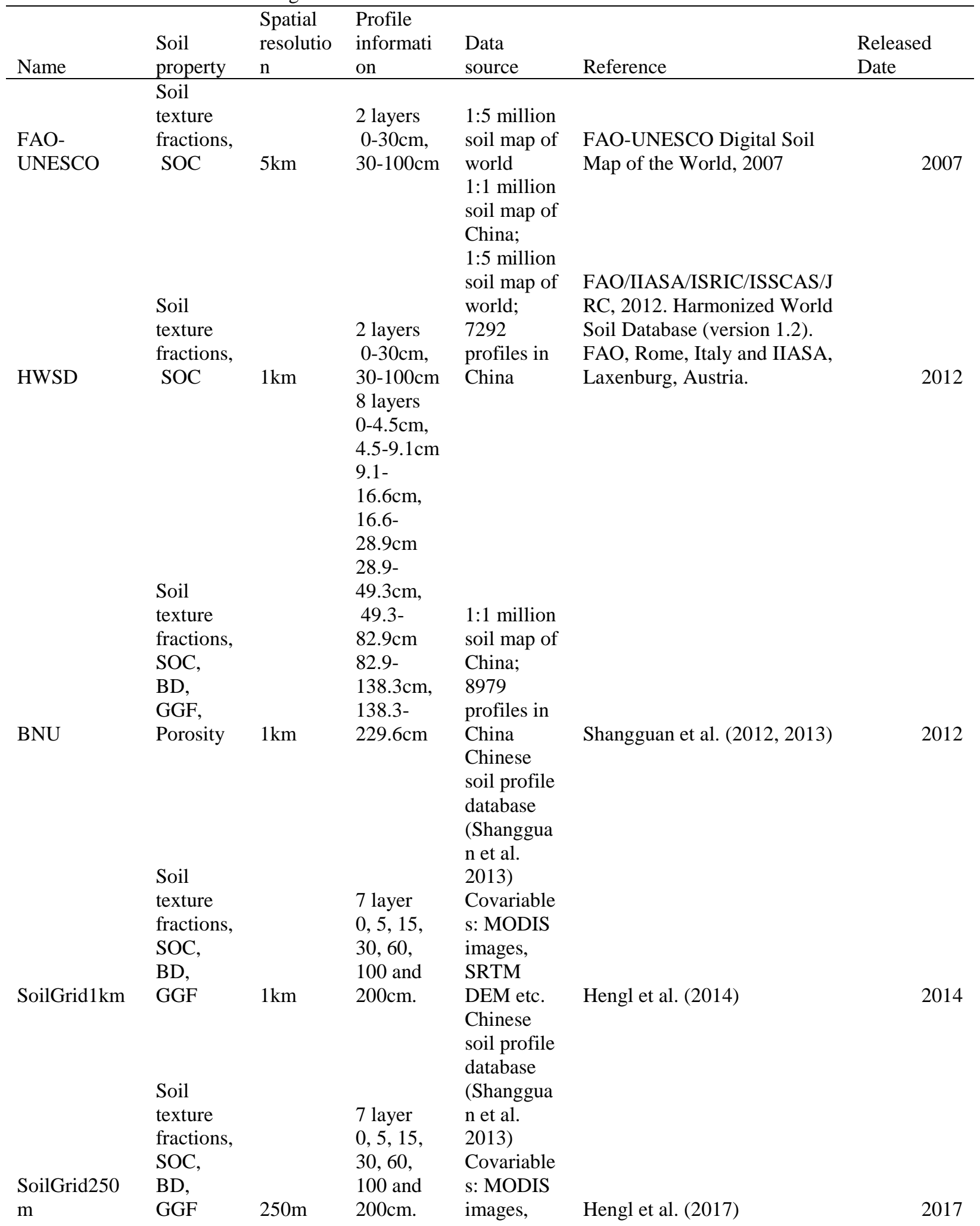


SRTM

DEM etc.

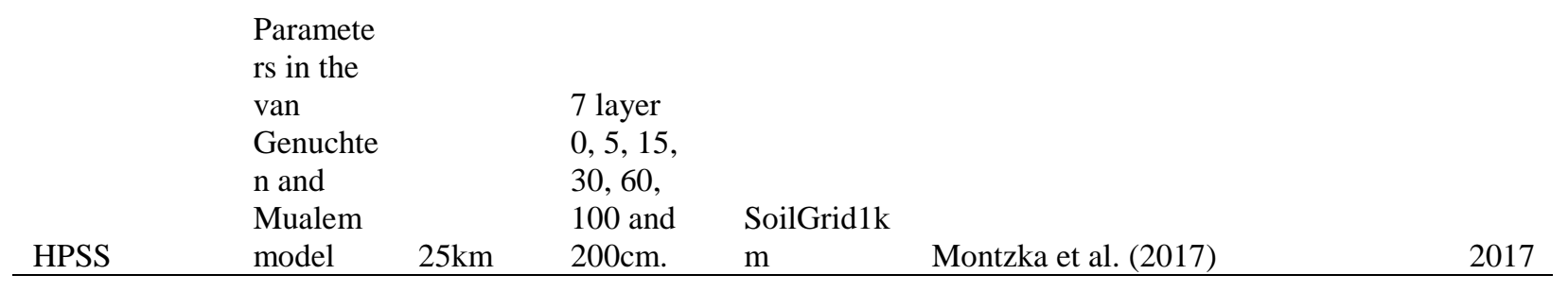

Table S2 Means and standard deviations of soil properties at different depths in the Ngari area

\begin{tabular}{lllll}
\hline Parameter & $5 \mathrm{~cm}$ & $10 \mathrm{~cm}$ & $20 \mathrm{~cm}$ & $40 \mathrm{~cm}$ \\
\hline Sand (\%) & $84.54 \pm 8.28$ & $86.19 \pm 8.63$ & $77.21 \pm 17.55$ & $78.81 \pm 17.93$ \\
Clay (\%) & $3.05 \pm 1.99$ & $2.73 \pm 2.03$ & $3.83 \pm 2.67$ & $3.27 \pm 2.71$ \\
Silt (\%) & $12.42 \pm 6.54$ & $11.08 \pm 6.93$ & $18.96 \pm 14.98$ & $17.93 \pm 15.41$ \\
GGF (\%) & $11.26 \pm 10.76$ & $11.77 \pm 15.71$ & $23.17 \pm 25.05$ & $18.75 \pm 20.17$ \\
SOC (\%) & $1.02 \pm 0.67$ & $0.7 \pm 0.49$ & $0.73 \pm 0.49$ & $0.79 \pm 0.67$ \\
Porosity (\%) & $33.49 \pm 2.78$ & $35.8 \pm 6.76$ & $31.4 \pm 7.2$ & $33.8 \pm 9.47$ \\
GD (mm) & $5.02 \pm 2.92$ & $5.23 \pm 2.47$ & $7.56 \pm 5.07$ & $4.96 \pm 1.7$ \\
FD (mm) & $0.22 \pm 0.1$ & $0.2 \pm 0.08$ & $0.23 \pm 0.19$ & $0.19 \pm 0.09$ \\
BD (g/cm $\left.{ }^{3}\right)$ & $1.56 \pm 0.13$ & $1.63 \pm 0.26$ & $1.6 \pm 0.26$ & $1.56 \pm 0.18$ \\
LogK $(\mathrm{m} / \mathrm{s})$ & & $-4.57 \pm 0.24$ & $-4.94 \pm 0.47$ & $-4.68 \pm 0.30$ \\
\hline
\end{tabular}

5 Table S3 Means and standard deviations of soil properties at different depths in the Naqu area

\begin{tabular}{llllll}
\hline Parameter & $5 \mathrm{~cm}$ & $10 \mathrm{~cm}$ & $20 \mathrm{~cm}$ & $40 \mathrm{~cm}$ & $50 \mathrm{~cm}$ \\
\hline Sand (\%) & $78.79 \pm 6.86$ & $81.48 \pm 13.49$ & $75.13 \pm 14.67$ & $75.93 \pm 10.64$ & $70.15 \pm 20.28$ \\
Clay (\%) & $4.41 \pm 1.63$ & $4.02 \pm 3.04$ & $5.84 \pm 3.87$ & $6.43 \pm 4.17$ & $7.29 \pm 6.39$ \\
Silt (\%) & $16.8 \pm 5.79$ & $14.5 \pm 10.46$ & $19.03 \pm 10.85$ & $17.64 \pm 7.09$ & $22.56 \pm 14.14$ \\
GGF (\%) & $12.69 \pm 13.11$ & $19.3 \pm 15.91$ & $34 \pm 25.97$ & $53.29 \pm 24.05$ & $57.43 \pm 22.43$ \\
SOC (\%) & $9.18 \pm 3.55$ & $8.17 \pm 3.95$ & $2.25 \pm 1.11$ & $1.61 \pm 0.93$ & $2.68 \pm 3.24$ \\
Porosity (\%) & $58.5 \pm 21.49$ & $45.67 \pm 6.81$ & $39.75 \pm 5.8$ & $29.5 \pm 6.61$ & $24.5 \pm 5.92$ \\
GD (mm) & $4.55 \pm 1.78$ & $3.96 \pm 1.2$ & $7.28 \pm 4.57$ & $7.75 \pm 4.99$ & $6.18 \pm 2.6$ \\
FD (mm) & $0.19 \pm 0.04$ & $0.21 \pm 0.07$ & $0.19 \pm 0.08$ & $0.22 \pm 0.05$ & $0.19 \pm 0.12$ \\
BD (g/cm $)$ & $1.01 \pm 0.48$ & $1.42 \pm 0.08$ & $1.64 \pm 0.17$ & $1.87 \pm 0.21$ & $2.11 \pm 0.18$ \\
LogK $(\mathrm{m} / \mathrm{s})$ & & $-5.20 \pm 0.25$ & $-5.09 \pm 0.50$ & $-5.20 \pm 0.77$ & $-6.12 \pm 0.99$ \\
\hline
\end{tabular}

Table S4 Means and standard deviations of soil properties at different depths in the Maqu area

\begin{tabular}{llllll}
\hline Parameter & $5 \mathrm{~cm}$ & $10 \mathrm{~cm}$ & $20 \mathrm{~cm}$ & $40 \mathrm{~cm}$ & $80 \mathrm{~cm}$ \\
\hline Sand (\%) & $26.95 \pm 10.55$ & $29.03 \pm 13.08$ & $29.21 \pm 12.61$ & $31.6 \pm 12.47$ & $34.83 \pm 17.06$ \\
Clay (\%) & $9.86 \pm 0.89$ & $9.95 \pm 0.91$ & $10.15 \pm 0.61$ & $10.43 \pm 0.89$ & $9.35 \pm 2.68$ \\
Silt (\%) & $63.19 \pm 10.08$ & $61.02 \pm 12.52$ & $60.65 \pm 12.48$ & $57.97 \pm 12.18$ & $55.82 \pm 14.95$ \\
SOC (\%) & $17.88 \pm 9.05$ & $12.16 \pm 6.23$ & $8.05 \pm 5.05$ & $4.13 \pm 3.14$ & $2.87 \pm 2.89$ \\
Porosity (\%) & $72.92 \pm 7.55$ & $65.57 \pm 7.57$ & $59.21 \pm 6.22$ & $50.96 \pm 7.5$ & $47.06 \pm 6.5$
\end{tabular}




\begin{tabular}{llllll}
$\mathrm{FD}(\mathrm{mm})$ & $0.03 \pm 0.01$ & $0.03 \pm 0.01$ & $0.03 \pm 0.01$ & $0.03 \pm 0.01$ & $0.04 \pm 0.02$ \\
$\mathrm{BD}\left(\mathrm{g} / \mathrm{cm}^{3}\right)$ & $0.76 \pm 0.22$ & $0.95 \pm 0.25$ & $1.23 \pm 0.19$ & $1.4 \pm 0.12$ & $1.49 \pm 0.18$ \\
$\log \mathrm{K}_{\mathrm{s}}(\mathrm{m} / \mathrm{s})$ & & $-5.5 \pm 0.32$ & $-5.55 \pm 0.44$ & $-6.52 \pm 0.3$ & $-5.65 \pm 0.97$ \\
\hline
\end{tabular}

10 Table S5 Absolute bias of estimated SWRCs from PTFs combined without BD scheme, with the measurements at 5 cm under three climate zones.

\begin{tabular}{lrrr}
\hline \multicolumn{1}{c}{ PTFs } & Ngari (arid) & Naqu (semi-arid) & \multicolumn{2}{c}{ Maqu (sub-humid) } \\
& Absolute Bias (cm3 cm-3) & Absolute Bias (cm3 cm-3) & Absolute Bias (cm3 cm-3) \\
\hline Cosby et al., 1984 & 0.03 & 0.09 & 0.23 \\
Cosby et al., 1984 & 0.03 & 0.09 & 0.20 \\
Saxton et al., 1986 & 0.09 & 0.08 & 0.21 \\
Campbell and Shiosawa, 1992 & 0.06 & 0.11 & 0.17 \\
Saxton et al., 2006 & 0.05 & 0.07 & 0.07 \\
Rawls and Brakenssiek 1985 & 0.06 & 0.16 & 0.30 \\
Wösten et al., (Class PTF) & 0.05 & 0.05 & 0.36 \\
Vereecken et al., 1989 & 0.02 & 0.11 & 0.36 \\
Wösten et al., 1999 & 0.05 & 0.07 & 0.25 \\
Rosetta1-H3 & 0.05 & 0.14 & 0.26 \\
Rosetta3-H3 & 0.04 & 0.12 & 0.40 \\
Weynants et al. 2009 & 0.05 & 0.07 & 0.23 \\
\hline
\end{tabular}


$\mathrm{CH}$

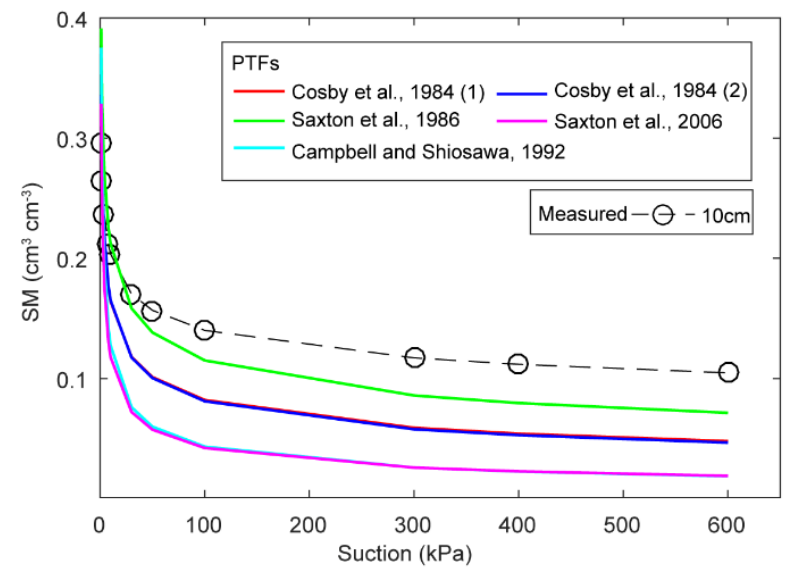

(a) Ngari (arid)

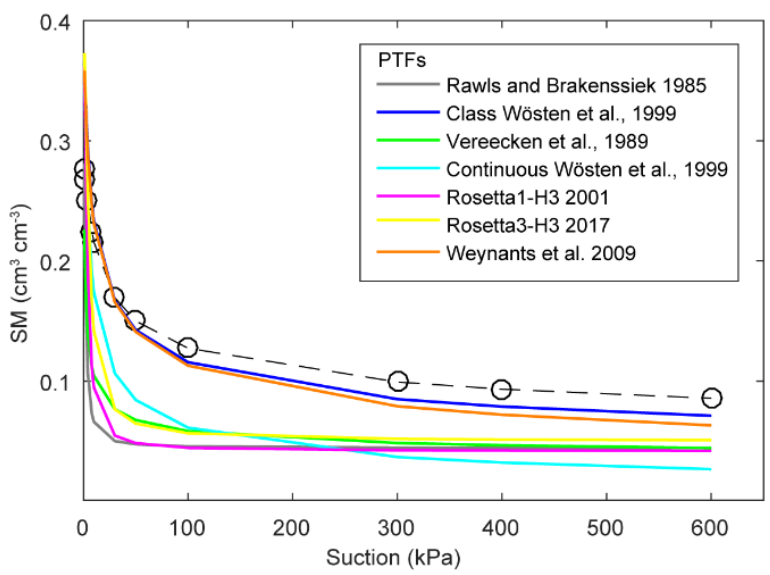

(b) Naqu (semi-arid)
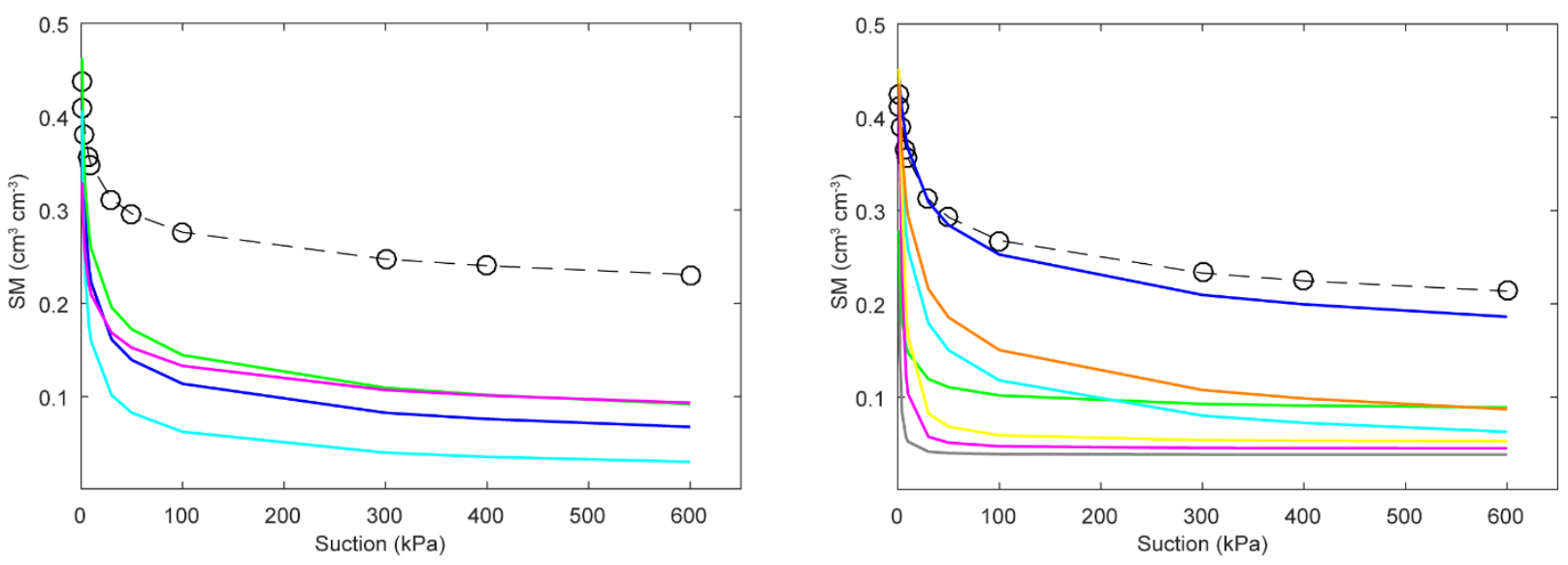

(c) Maqu (sub-humid)

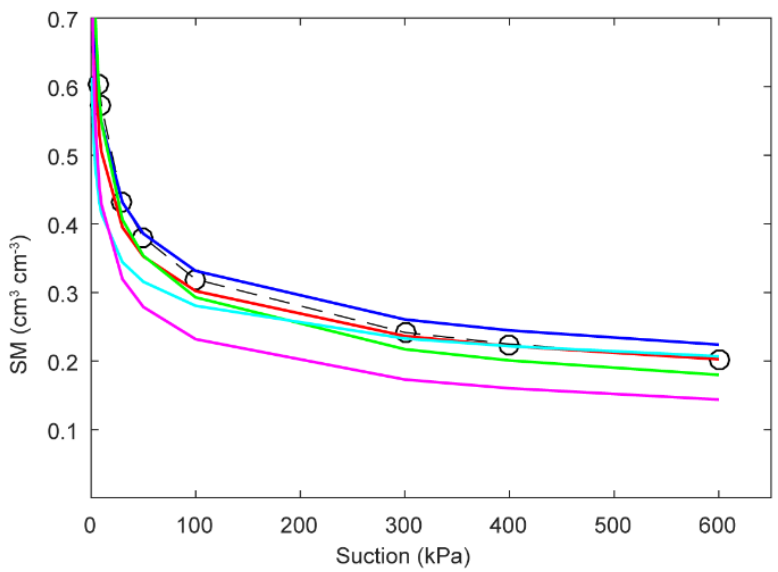

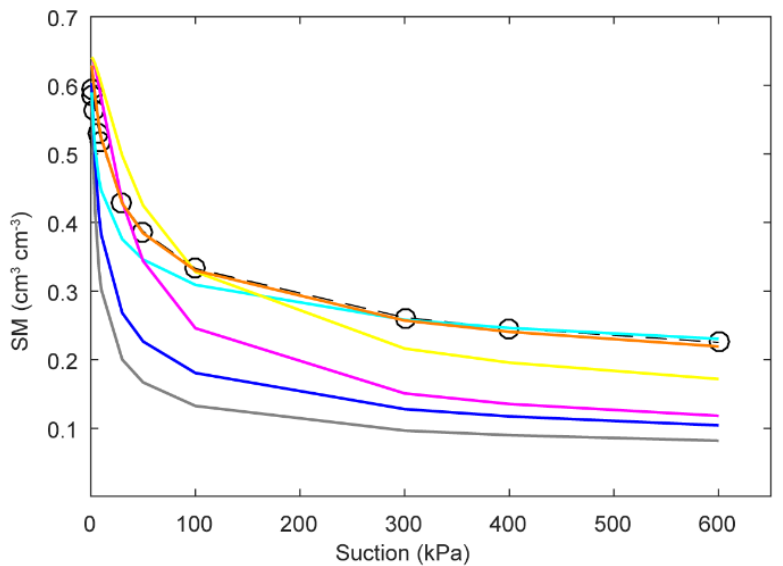

Figure S1-1 Comparisons between estimated SWRCs from PTFs combined with the BD scheme, and the measurement determined SWRCs at $10 \mathrm{~cm}$ for three climate zones. It is to note that the SWRC estimated from Vereecken et al. (1989) PTFs was out of range over the sub-humid zone and was removed (right figure in Fig. S1$1 \mathrm{C})$. 
$\mathrm{CH}$

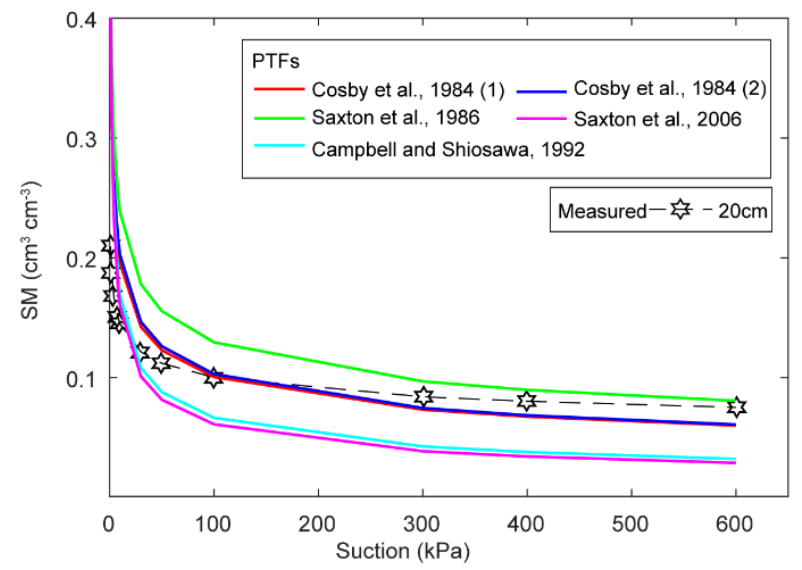

(a) Ngari (arid)

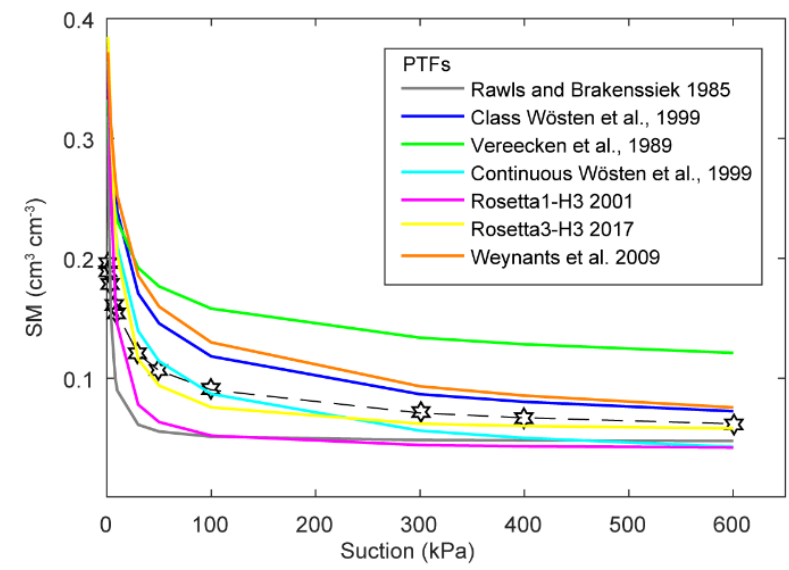

(b) Naqu (semi-arid)
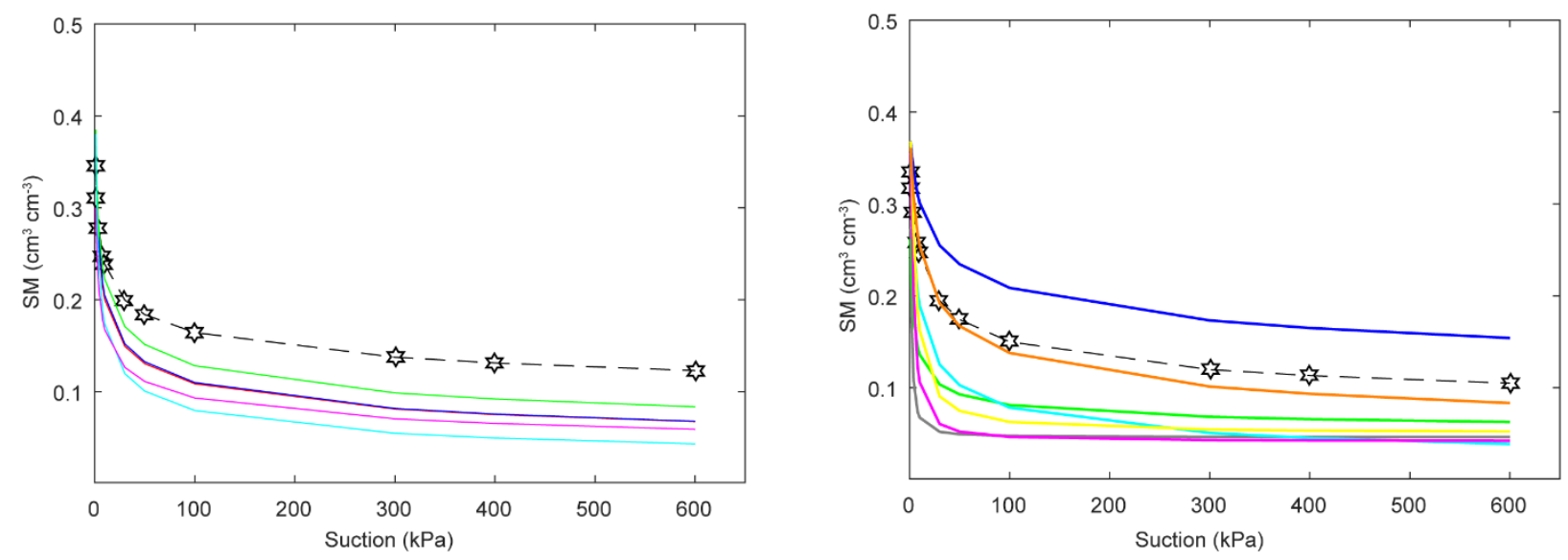

(c) Maqu (sub-humid)
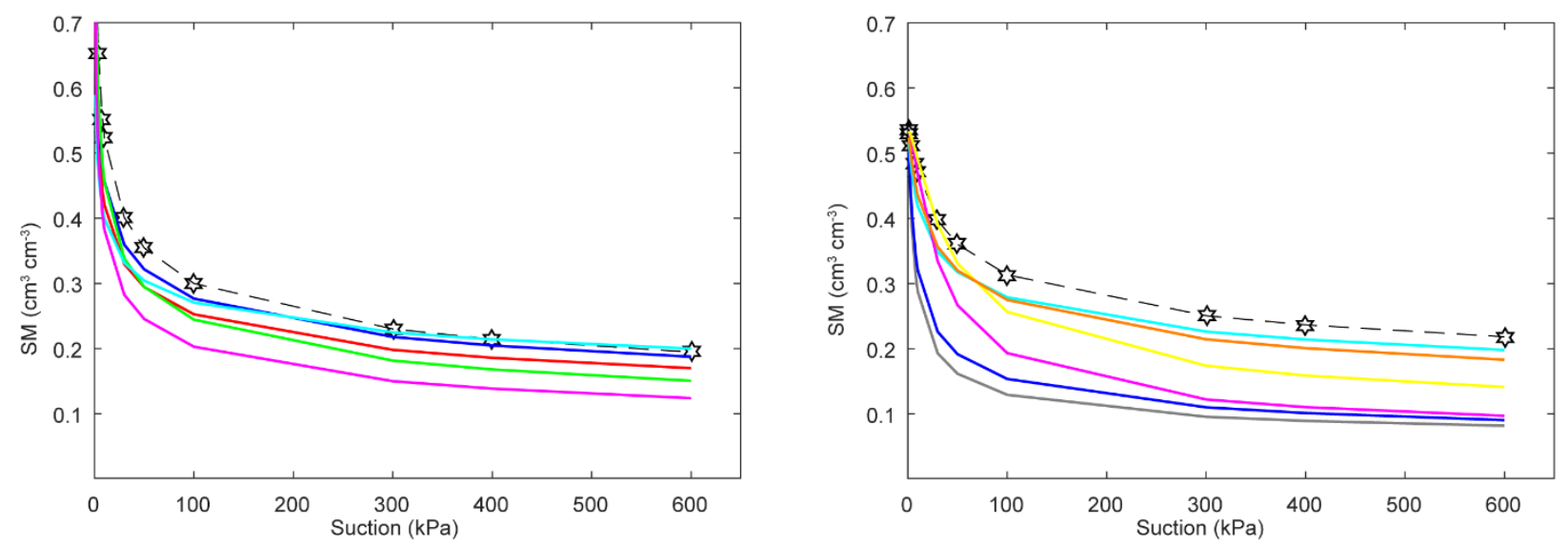

Figure S1-2 Comparisons between estimated SWRCs from PTFs combined with the BD scheme, and the measurement determined SWRCs at $20 \mathrm{~cm}$ for three climate zones. It is to note that the SWRC estimated from Vereecken et al. (1989) PTFs was out of range over the sub-humid zone and was removed (right figure in Fig. S12C). 
$\mathrm{CH}$

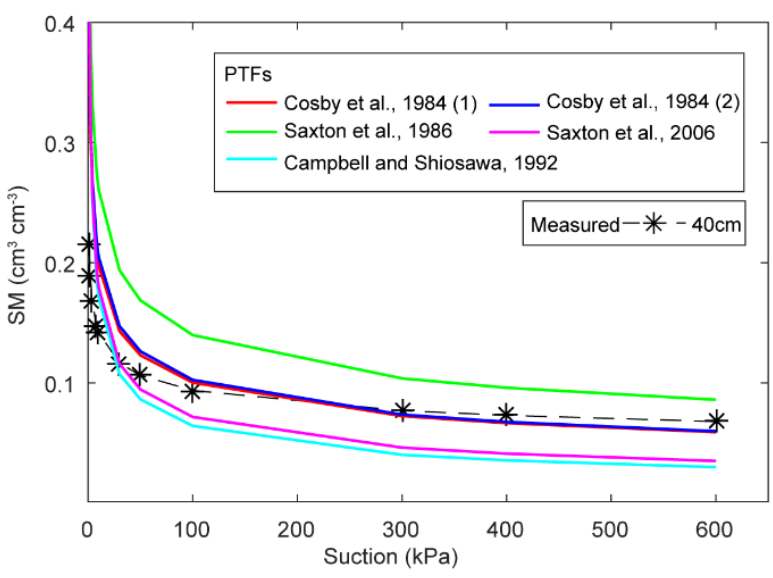

(a) Ngari (arid)

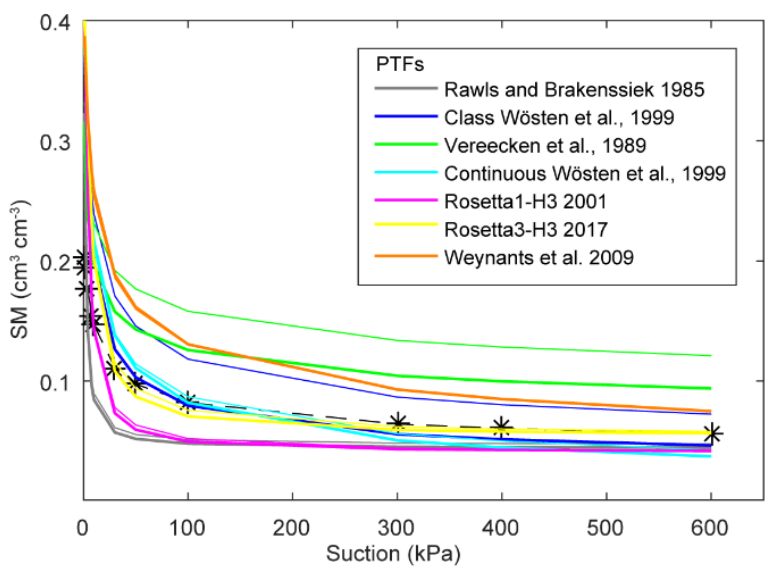

(b) Naqu (semi-arid)

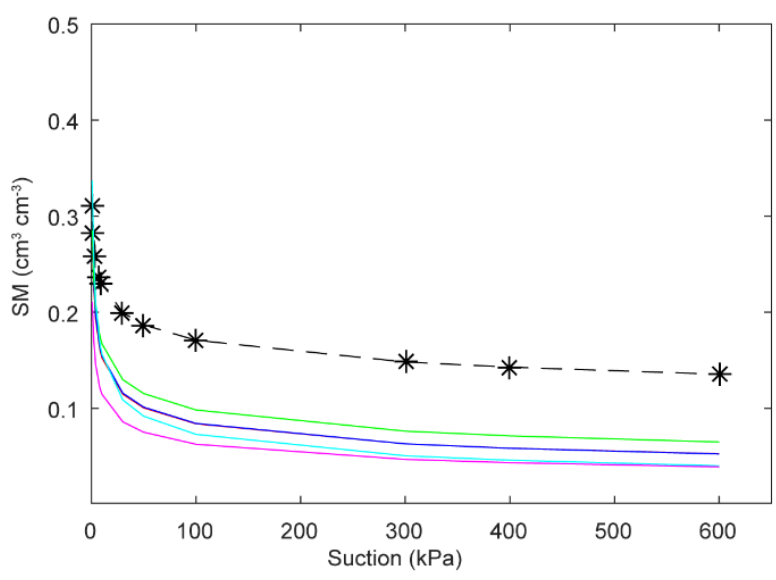

(c) Maqu (sub-humid)
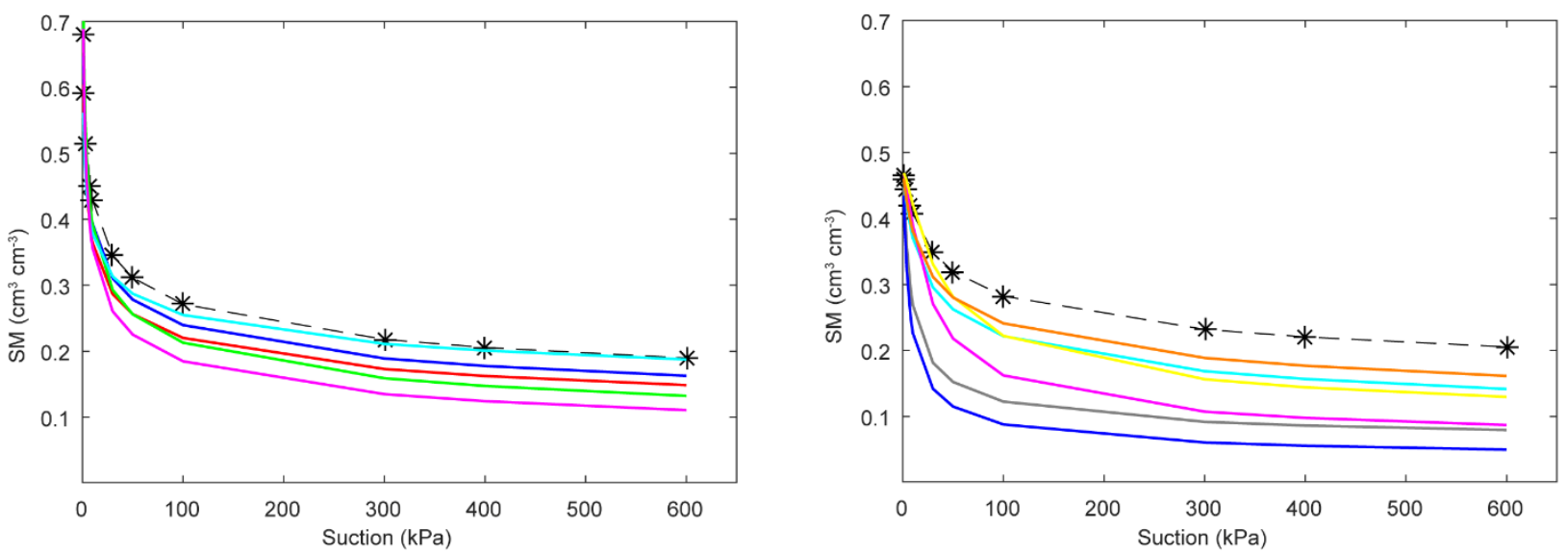

25 Figure S1-3 Comparisons between estimated SWRCs from PTFs combined with the BD scheme, and the measurement determined SWRCs at $40 \mathrm{~cm}$ for three climate zones. It is to note that the SWRC estimated from Vereecken et al. (1989) PTFs was out of range over the sub-humid zone and was removed (right figure in Fig. S1- 


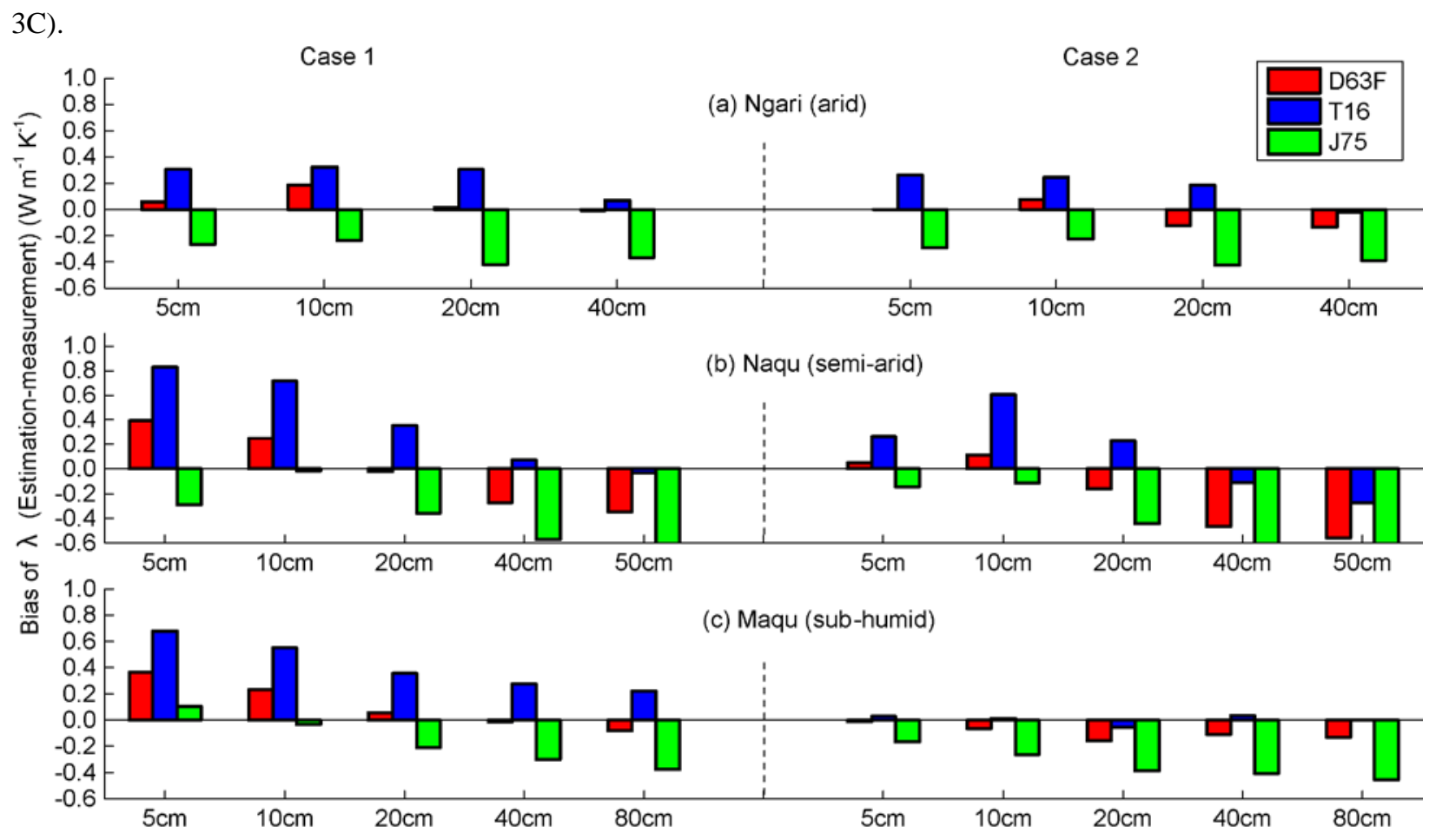

30 Figure S2 Biases of $\lambda$ estimates based on D63F, T16 and J75 schemes combined with the Cosby-S scheme (Cosby PTFs) in the profile over the three climate zones with the measurements. Case 1 is the bias derived from schemes not considering gravel impact parameterization for the arid and semi-arid zone and SOC impact parameterization for the semi-humid zone. Case 2 is the bias with these parameterizations consideration. 
List of Abbreviations:

SHP/STP Soil hydraulic and thermal properties

LSM Land surface model

TP the Tibetan Plateau

SWRC Soil Water Retention Curve

$40 \quad K_{s} \quad$ Saturated hydraulic conductivity

$\lambda$ Thermal conductivity

SM Soil Moisture

ST Soil temperature

Tibet-Obs The Tibetan Plateau Observatory of plateau scale soil moisture and soil temperature

45 the CH model The Clapp and Hornberger (1978) formulation

the VG model The Van Genuchten (1980) formulation

PTFs Pedotransfer functions

H-TESSEL The Hydrology-Tiled European Centre for Medium-Range Weather Forecasts Scheme for Surface Exchanges over Land (H-TESSEL)

50 SOC Soil organic matter content

BD Bulk density

GGF Gravimetric gravel fraction

USDA The United States Department of Agriculture

FD The mean particle diameter of fine component

55 GD The mean particle diameter of gravels

BNU dataset Soil dataset from Shangguan et al. (2013) released by Beijing Normal University

FC Field Capacity

PWP Permanent Wilting Point

D Soil diffusivity

$60 K \quad$ Soil conductivity 